\title{
Detecção de Xanthomonas axonopodis pv. phaseoli em sementes de feijoeiro provenientes do Estado do Paraná, Brasil
}

\author{
João Pereira Torres ${ }^{1}$, Tadeu Antônio Fernandes da Silva Júnior ${ }^{2,3}$, Antonio Carlos Maringonii ${ }^{2,4}$
}

${ }^{1}$ UENP - Universidade Estadual do Norte do Paraná, Faculdades Luiz Meneghel, Departamento de Patologia Geral, CP 261, 86.360-000, Band eirantes, PR. ${ }^{2}$ UNESP - Universidade Estadual Paulista Júlio de Mesquita Filho, Faculdade de Ciências Agronômicas, Departamento de Produção Vegetal, CP 237, 18.603-970, Botucatu, SP. ${ }^{3}$ Bols ista da CAPES. ${ }^{4}$ Bols ista de produtividade em pesquis a do CNPq.

Autor para correspondência: Antonio Carlos Maringoni. E-mail: maringoni@fca.unesp.br

Data de chegada: 11/04/2008. Aceito para publicação em: 29/10/2008

\section{RESUMO}

Torres, J. P.; Silva Júnior, T. A. F.; Maringoni, A.C. Detecção de Xanthomonas axonopodis pv. phaseoli em sementes de feijoeiro provenientes do Estado do Paraná, Brasil. Sum ma Phytopathologica, v.35, n.2, p.136-139, 2009

O crestamento bacteriano comum do feijoeiro causado por Xanthomonas axonopodis pv. phaseoli (Xap) é a principal doença do feijoeiro comum no Brasil. O patógeno encontra-se disseminado em todas as regiões produtoras do país, porém com maior importância nos estados do Paraná, Rio de Janeiro, São Paulo e na região do Brasil Central, sobretudo na safra das águas. Dentre os vários meios de sobrevivência e disseminação da Xap, a semente representa o mais eficiente. Aqualidade sanitária de 34 amostras de sementes de feijoeiro produzidas no estado do Paraná, nas safras 1998/99 e 1999, foram avaliadas quanto à presença de Xap em macerados de sementes plaqueados em meio semi-seletivo. Cinqüenta por cento dos lotes de sementes foram portadores de Xap com incidência de $0,1 \%$ a $1,7 \%$.

Palavras-chave adicionais: crestamento bacteriano comum do feijoeiro, Phaseolus vulgaris, feijão, bactéria.

\section{ABSTRACT}

Torres, J. P.; Silva Júnior, T. A. F.; Maringoni, A.C. Detection of Xanthomonas axonopodis pv. phaseoli in common bean seeds from the state of Paraná (Brazil). Sum ma Phytopathologica, v.35, n.2, p.136-139, 2009

The common bacterial blight of bean, caused by Xanthomonas axonopodis pv. phaseoli (Xap), is a major disease of common beans in Brazil. Even though this pathogen is disseminated in all production regions of the country, it has caused major damages in the states of Paraná, Rio de Janeiro and São Paulo and in Central Region of Brazil, particularly during the rainy season. Infected bean seeds are most effective means of survival and dissemination of the Xap. The health quality of 34 samples of seeds lots of common beans produced in the state of Paraná during 1998/99 and 1999 were evaluated to the presence of Xap in seed macerates plated on a semi-selective culture medium. Fifty percent of the seed lots were carrying out by Xap with an incidence range of $0.1 \%$ to $1.7 \%$.

Keywords: bean commom bacterial blight, Phaseolus vulgaris, bacteria

A cultura do feijoeiro encontra-se amplamente distribuída em todos os estados brasileiros, nos mais variados graus de tecnific ação, desde cultura de subsistência até as de alta tecnologia como irrigação sob pivô central, cultivares com alta produtividade e resistência a patógenos, adubações equilibradas e controle satisfatório de pragas, doenças e plantas daninhas.

Dentre as doenças que podem representar perdas significativas na produção, dependendo das condições ambientais prevalecentes, encontra-se o crestamento bacteriano comum (CBC), incitado por Xanthomonas axonopodis pv. phaseoli (Xap), patógeno diss eminado em praticamente todas as regiões produtoras, porém com maior importância nos Estados do Paraná, Rio de Janeiro, São Paulo e na região do Brasil Central, sobretudo na safra das águas (25).

Em levantamento realizado no Estado do Paraná, Maringoni \& Komori (08) constataram a ocorrência do CBC em praticamente todas as regiões do Estado, situação decorrente da suscetibilidade das cultivares e do uso de sementes contaminadas/infectadas, aliadas às condições climáticas favoráveis ao desenvolvimento da doença.
Na Tanzânia, Mabagala (7) detectou sementes infectadas provenientes de plantas assintomáticas inoculadas artificialmente de cultivares resistentes de feijoeiro, observando que essas sementes podem representar importante papel na epidemiologia da doença.

Em estudos epidemiológicos, Wallen \& Sutton (26), no Canadá, verificaram que $0,5 \%$ de sementes infectadas foram suficientes para manifestação de epidemia. Em Uganda, na África, Opio et al. (13), em condições de campo, constataram que a população mínima para iniciar a infecção foi de $10^{2}$ ufc/semente e que $0,2 \%$ de sementes infectadas provocaram severa epidemia. Valarini et al. (24) observaram que a emergência de plântulas não foi significativamente afetada utilizando sementes com mais de $10 \%$ de infecção, porém níveis de infecção nas sementes a partir de 5\% reduziram a produção. Segundo Maringoni et al. (11), para algumas cultivares de feijoeiro, o desenvolvimento de epidemia do CBC dependeu mais do nível de resistência horizontal das cultivares e das condições climáticas do que da quantidade de inóculo presente nas sementes.

Quanto à qualidade fitossanitária das sementes de feijão no Brasil, 
no que diz respeito à presença de Xap, Valarini \& Spadotto (23) detectaram a bactéria em $8 \%$ das amostras analisadas, de um total de 25 amostras de sementes fiscalizada/certificada, oriundas da região de Guaíra, Estado de São Paulo, utilizadas na safra de 1992/93. Valarini (19), também trabalhando com amostras de sementes do Estado de São Paulo, encontrou índices de infecção que variaram de $0,1 \%$ a 1,1\% de sementes com Xap. Ito et al. (5) ao analis arem lotes de sementes de feijoeiro das safras de 1991 e 1993 do Estado deSão Paulo, observaram, respectivamente que $5,3 \%$ e $30,6 \%$ dos lotes de sementes estavam infectados por Xap.

Em que pese os diversos meios de sobrevivênc ia e disseminação da Xap, a semente representa o mais eficiente (29), pois a bactéria pode localizar-se no interior, na superficie, ou simplesmente junto, acompanhando as sementes (17). O tempo de sobrevivência da Xap, em sementes, foi variável conforme relatado em algumas pesquisas: dois (2), seis (27) e dez anos (29).

Os resultados mais efetivos de controle do $\mathrm{CBC}$ podem ser obtidos com uma combinação de medidas como o uso de sementes livres do patógeno $(16,29)$, cultivares resistentes $(4,9,15)$ e rotação de culturas (16). A pulverização de produtos químicos não tem apresentado resultados satisfatórios no controle do $\mathrm{CBC}$ em condições de campo (1; 14).

O presente trabalho teve por objetivo avaliar a qualidade sanitária de sementes fiscalizadas de feijão produzidas no Estado do Paraná, em duas safras agrícolas quanto à presença de Xap.

\section{MATERIAL E MÉTODOS}

Foram obtidas 34 amostras de sementes de feijão produzidas nas safras 1998/99 e 1999 no estado do Paraná, conforme Tabela 1, as quais foram submetidas à análise vis ando a detecção de Xap.

O método utilizado para detecção da bactéria nas sementes de feijoeiro foi descrito por Maringoni (12) e Silva \& Maringoni (18), adaptado de Valarini (20) e Valarini \& Menten (21; 22). Para cada amostra de sementes foram feitas 11 sub-amostras assim constituídas: uma de 500 sementes, cinco de 100 sementes e cinco de 10 sementes. As sub-amostras foram submetidas à maceração em erlemmeyers contendo água destilada e esterilizada com volume pré-determinado, conforme a Tabela 2.

As sementes permaneceram em maceração sob refrigeração à temperatura aproximada de $5^{\circ} \mathrm{C}$, durante 18 a 24 horas. Em seguida, os frascos foram agitados manualmente e as suspensões obtidas da maceração das sementes foram semeadas, com auxílio de uma alça de platina, através de estrias, em placas de Petri contendo meio semiseletivo para Xap, conforme Maringoni et al. (10). As placas de Petri foram divididas em dois campos, marcando-se o fundo da placa com caneta hidrográfica em dois setores. Assim, foram feitas, em cada placa, duas semeaduras, totalizando duas placas com quatro setores para cada sub-amostra. Desse modo obteve-se 22 placas com 44 repicagens, para cada amostra de semente analisada. Paralelamente, foi realizada a repicagem de um isolado puro padrão de Xap, para efeito de comparação no momento da avaliação. As placas foram incubadas a $28^{\circ} \mathrm{C}$, por um período de quatro a cinco dias.

A avaliação foi realizada imediatamente após o período de incubação, observando-se as características culturais e morfológicas das colônias bacterianas, comparando-se com o isolado padrão e verificando-se a hidrólise de amido, após adição de lugol à superfície do meio de cultura $(10,12,18)$. A partir dos resultados positivos para cada amostra analisada, foi feita a quantificação de Xap na semente,
Tabela 1. Amostra, cultivar, lote e safra de sementes de feijoeiro fiscalizadas produzidas no Estado do Paraná.

\begin{tabular}{|c|c|c|c|}
\hline Amostra & Cultivar & Lote & Safra \\
\hline 01 & IAPAR 81 & único & 1999 \\
\hline 02 & MD-811 & único & 1999 \\
\hline 03 & Carioquinha & único & 1999 \\
\hline 04 & FT Nobre & $04 / 99$ & $98 / 99$ \\
\hline 05 & IAPAR 44 & $02 / 99$ & $98 / 99$ \\
\hline 06 & FT Nobre & $05 / 99$ & $98 / 99$ \\
\hline 07 & FT Nobre & $01 / 99$ & $98 / 99$ \\
\hline 08 & FT Nobre & $03 / 99$ & $98 / 99$ \\
\hline 09 & FT Nobre & $02 / 99$ & $98 / 99$ \\
\hline 10 & FT Nobre & 602.0 .4 & 1999 \\
\hline 11 & Carioca & 2.0 .4 & 1999 \\
\hline 12 & Pérola & 157.2 .4 & 1999 \\
\hline 13 & Pérola & 107 & 1999 \\
\hline 14 & Rudá & 201 & 1999 \\
\hline 15 & FT Nobre & 305 & 1999 \\
\hline 16 & IAPAR 81 & $01 / 01$ & $98 / 99$ \\
\hline 17 & IAPAR 81 & 005 & $98 / 99$ \\
\hline 18 & IAPAR 81 & 004 & $98 / 99$ \\
\hline 19 & FT Nobre & 01 & 1999 \\
\hline 20 & FT Nobre & 02 & 1999 \\
\hline 21 & FT Bonito & 03 & 1999 \\
\hline 22 & FT Nobre & 04 & 1999 \\
\hline 23 & FT Nobre & 05 & 1999 \\
\hline 24 & FT Nobre & 06 & 1999 \\
\hline 25 & FT Bonito & 07 & 1999 \\
\hline 26 & FT Bonito & 08 & 1999 \\
\hline 27 & IAPAR 81 & 02 & $98 / 99$ \\
\hline 28 & FT Nobre & 20 & $98 / 99$ \\
\hline 29 & Pérola & 13 & $98 / 99$ \\
\hline 30 & FT Nobre & 16 & $98 / 99$ \\
\hline 31 & IAPAR 81 & 06 & $98 / 99$ \\
\hline 32 & Pérola & 14 & $98 / 99$ \\
\hline 33 & FT Nobre & 15 & $98 / 99$ \\
\hline 34 & FT Nobre & 05 & $98 / 99$ \\
\hline
\end{tabular}

por meio da estimativa do número mais provável (NMP) de sementes portadoras da bactéria, expressa em percentagem, empregando-se a Tabela $3(12,18,20,21,22)$.

Alguns isolados obtidos das amostras de sementes (três isolados por amostra) com característic as culturais e morfológicas típicas de Xap foram submetidas a teste de patogenicidade na cultivar de feijoeiro IAPAR 57 (18).

Tabela 2. Volume de água destilada esterilizada utilizado na maceração de sementes de feijoeiro para a detecção de Xanthomonas axonopodis pv. phaseoli.

\begin{tabular}{cccc}
\hline $\begin{array}{c}\mathrm{N}^{\circ} \text { de } \\
\text { sub-amostras }\end{array}$ & $\begin{array}{c}\mathrm{N}^{\circ} \text { de } \\
\text { sementes }\end{array}$ & $\begin{array}{c}\text { Volume de } \\
\text { água }(\mathrm{mL})\end{array}$ & $\begin{array}{c}\text { Erlenmeyer } \\
(\mathrm{mL})\end{array}$ \\
\hline Uma & 500 & 180 & 500 \\
Cinco & 100 & 35 & 250 \\
Cinco & 10 & 10 & 125 \\
\hline
\end{tabular}

Fonte: Valarini (20) 
Tabela 3. Quantificação da presença de Xanthomonas axonopodis pv. phaseoli em amostras de sementes de feijoeiro.

\begin{tabular}{|c|c|c|c|c|c|}
\hline \multicolumn{3}{|c|}{$\begin{array}{l}\text { Número de sub-amostras } \\
\text { com resultado positivo }\end{array}$} & \multirow{2}{*}{$\begin{array}{l}\text { Número mais provável } \\
\text { (NMP) de semente } \\
\text { portadora do patógeno (\%) }\end{array}$} & \multicolumn{2}{|c|}{$\begin{array}{l}\text { Limites do NMP/ } \\
100 \text { sementes }\end{array}$} \\
\hline $\begin{array}{c}1 \text { a } 500 \\
\text { sementes }\end{array}$ & $\begin{array}{l}5 \text { a } 100 \\
\text { sementes }\end{array}$ & $\begin{array}{c}5 \text { a } 10 \\
\text { sementes }\end{array}$ & & Inferior & Superior \\
\hline 0 & 0 & 1 & 0,1 & $<0,05$ & 0,4 \\
\hline 0 & 0 & 2 & 0,2 & 0,05 & 0,6 \\
\hline 0 & 1 & 0 & 0,1 & 0,05 & 0,4 \\
\hline 0 & 1 & 1 & 0,2 & 0,05 & 0,6 \\
\hline 0 & 1 & 2 & 0,3 & 0,05 & 0,8 \\
\hline 0 & 2 & 0 & 0,2 & 0,05 & 0,6 \\
\hline 0 & 2 & 1 & 0,3 & 0,05 & 0,8 \\
\hline 0 & 2 & 2 & 0,4 & 0,05 & 1,1 \\
\hline 0 & 3 & 0 & 0,3 & 0,05 & 0,8 \\
\hline 0 & 3 & 1 & 0,5 & 0,05 & 1,3 \\
\hline 0 & 4 & 0 & 0,5 & 0,05 & 1,3 \\
\hline 1 & 0 & 0 & 0,1 & 0,05 & 0,4 \\
\hline 1 & 0 & 1 & 0,3 & 0,05 & 0,8 \\
\hline 1 & 0 & 2 & 0,4 & 0,05 & 1,1 \\
\hline 1 & 0 & 3 & 0,6 & 0,05 & 1,5 \\
\hline 1 & 1 & 0 & 0,3 & 0,05 & 0,8 \\
\hline 1 & 1 & 1 & 0,5 & 0,05 & 1,3 \\
\hline 1 & 1 & 2 & 0,7 & 0,1 & 1,7 \\
\hline 1 & 1 & 3 & 0,9 & 0,2 & 2,1 \\
\hline 1 & 2 & 0 & 0,5 & 0,05 & 1,3 \\
\hline 1 & 2 & 1 & 0,7 & 0,1 & 1,7 \\
\hline 1 & 2 & 2 & 1,0 & 0,3 & 2,3 \\
\hline 1 & 2 & 3 & 1,2 & 0,3 & 2,8 \\
\hline 1 & 3 & 0 & 0,8 & 0,2 & 1,9 \\
\hline 1 & 3 & 1 & 1,1 & 0,3 & 2,6 \\
\hline 1 & 3 & 2 & 1,4 & 0,4 & 3,4 \\
\hline 1 & 3 & 3 & 1,8 & 0,5 & 5,3 \\
\hline 1 & 3 & 4 & 2,1 & 0,6 & 6,6 \\
\hline 1 & 4 & 0 & 1,3 & 0,4 & 3,1 \\
\hline 1 & 4 & 1 & 1,7 & 0,5 & 4,7 \\
\hline 1 & 4 & 2 & 2,2 & 0,7 & 6,9 \\
\hline 1 & 4 & 3 & 2,8 & 0,9 & 8,5 \\
\hline 1 & 4 & 4 & 3,5 & 1,2 & 10,1 \\
\hline 1 & 4 & 5 & 4,3 & 1,5 & 11,7 \\
\hline 1 & 5 & 0 & 2,4 & 0,8 & 7,5 \\
\hline 1 & 5 & 1 & 3,5 & 1,2 & 10,1 \\
\hline 1 & 5 & 2 & 5,4 & 1,8 & 13,8 \\
\hline 1 & 5 & 3 & 9,2 & 9,2 & 21,7 \\
\hline 1 & 5 & 4 & 16,1 & 3,1 & $>45,0$ \\
\hline
\end{tabular}

Fonte: Swaroop (1951), conforme Valarini (20) e Valarini \& Menten (21;22)

\section{RESULTADOS E DISCUSSÃO}

Pôde-se observar que dos 34 lotes de sementes de feijoeiro analisados, 17 estavam transportando Xap, ou seja, 50\% dos lotes.

Os isolados bacterianos obtidos desses lotes de sementes, submetidos a teste de patogenicidade, foram patogênicos à cultivar IAPAR 57, sendo identificados como Xap.
Tabela 4. Avaliação da presença de Xanthomonas axonopodis pv. phaseoli em 34 lotes de sementes de feijoeiro fiscalizadas de várias regiões do Estado do Paraná, safras 1998/99 e 1999/99.

\begin{tabular}{|c|c|c|c|c|}
\hline \multirow{2}{*}{ Amostra } & \multicolumn{3}{|c|}{$\begin{array}{l}\text { Número de sub-amostra } \\
\text { com resultado positivo }\end{array}$} & \multirow{2}{*}{$\begin{array}{l}\text { Número mais provável (NMP) de } \\
\text { semente portadora do patógeno }(\%)\end{array}$} \\
\hline & $\begin{array}{c}1 \text { a } 500 \\
\text { sementes }\end{array}$ & $\begin{array}{c}5 \text { a } 100 \\
\text { sementes }\end{array}$ & $\begin{array}{c}5 \text { a } 10 \\
\text { sementes }\end{array}$ & \\
\hline 01 & 1 & 3 & 0 & 0,8 \\
\hline 02 & 0 & 2 & 0 & 0,2 \\
\hline 03 & 0 & 0 & 1 & 0,1 \\
\hline 04 & 1 & 3 & 1 & 1,1 \\
\hline 05 & 0 & 0 & 0 & 0 \\
\hline 06 & 0 & 2 & 0 & 0,2 \\
\hline 07 & 0 & 1 & 0 & 0,1 \\
\hline 08 & 0 & 4 & 0 & 0,5 \\
\hline 09 & 0 & 0 & 0 & 0 \\
\hline 10 & 1 & 4 & 1 & 1,7 \\
\hline 11 & 0 & 0 & 0 & 0 \\
\hline 12 & 0 & 0 & 0 & 0 \\
\hline 13 & 0 & 0 & 0 & 0 \\
\hline 14 & 1 & 2 & 0 & 0,5 \\
\hline 15 & 0 & 1 & 0 & 0,1 \\
\hline 16 & 0 & 1 & 0 & 0,1 \\
\hline 17 & 1 & 3 & 0 & 0,8 \\
\hline 18 & 0 & 1 & 0 & 0,1 \\
\hline 19 & 0 & 0 & 0 & 0 \\
\hline 20 & 0 & 0 & 0 & 0 \\
\hline 21 & 0 & 0 & 0 & 0 \\
\hline 22 & 0 & 1 & 1 & 0,2 \\
\hline 23 & 1 & 3 & 0 & 0,3 \\
\hline 24 & 0 & 4 & 0 & 0,5 \\
\hline 25 & 0 & 0 & 0 & 0 \\
\hline 26 & 0 & 0 & 0 & 0 \\
\hline 27 & 0 & 0 & 0 & 0 \\
\hline 28 & 0 & 0 & 0 & 0 \\
\hline 29 & 0 & 0 & 0 & 0 \\
\hline 30 & 0 & 0 & 0 & 0 \\
\hline 31 & 0 & 0 & 0 & 0 \\
\hline 32 & 0 & 0 & 0 & 0 \\
\hline 33 & 1 & 1 & 0 & 0,3 \\
\hline 34 & 0 & 0 & 0 & 0 \\
\hline
\end{tabular}

Aliando sobrevivência e disseminação de Xap, a semente representa um dos mais importantes veículos de disseminação, tanto a curtas quanto a longas distâncias (29), pois a bactéria pode localizarse no interior da semente ou estar aderida à superfície, acompanhando a semente, em restos de tecidos do hosped eiro (17).

Dependendo das condições edáficas e da suscetibilidade da cultivar de feijoeiro a Xap, $0,2 \%$ ou $0,5 \%$ de sementes com esta bactéria é inóculo suficiente para causar epidemia da doença em campo $(13,26)$. Para as cultivares avaliadas por Valarini et al. (24), sementes com incidência de Xap a partir de $10 \%$ originaram lavouras com redução na produção.

Pela importância das sementes como instrumento de sobrevivência e veículo de inóculo, $50 \%$ dos lotes com a presença de Xap é um índice muito elevado. Nos 17 lotes emque a bactéria foidetectada, a incidência 
de sementes com Xap variou de $0,1 \%$ a $1,7 \%$. Considerando-se que o mínimo de $0,2 \%$ de sementes de feijoeiro com Xap seja suficiente para dar início à epidemia da doença em campo (13), pelo menos 12 lotes de sementes avaliadas estariam comprometidos para o cultivo. A quantidade de lotes de sementes com Xap observadas neste estudo é superior àqueles encontrados por Valarini (20) e Ito et al. (5) no Estado de São Paulo, embora esses autores tenham utilizado metodologias diferentes para a detecção da bactéria nas sementes de feijoeiro analis adas.

Os dados obtidos para o estado do Paraná reafirmam observações anteriores (8), no sentido da ampla disseminação de Xap nas regiões produtoras desse estado, em função da combinação de fatores tais como a susc etibilidade das cultivares e o uso de sementes portadoras de Xap, aliados às cond ições climátic as favoráveis à doença.

Por ser o CBC uma doença de difícil controle, a produção de sementes com alto padrão de sanidade constitui-se emuma das medidas mais eficientes de controle $(3,28)$. Assim, os dados aqui obtidos recolocam a discussão da eficiência ou a oportunidade de padronização de parâmetros de campos para produção de sementes tais como, nível de to lerância de plantas infectadas de $20 \%$, modelo ou padrão de trânsito de vis torias nas lavouras, etc. (6), bem como a nec essidade de implantação de testes laboratoriais para a detecção de Xap em sementes, como complemento aos trabalhos de inspeções de campo.

\section{REFERÊNCIAS BIBLIOGRÁFICAS}

1. Arnaud-Santana, E., Coyne, D. P., Beaver, J. S., Zaiter, H. Z. Effect of photoperiod and temperature on commom blight disease of commom beans (Phaseolus vulgaris L.). Euphytica, v. 66, p. 211-6, 1993.

2. Burkholder, W. H. The bacterial blight of bean: a systemic disease. Phytopathology, St. Paul, v. 11, p. 61-9, 1921.

3. Calzolari, A. Maculatura alonata e comune del fagiolo. Informatore Agrario, Verona, v. 53, n. 25, p. 66-7, 1997.

4. Gilbertson, R. L., Rand, R. E., Carlson, E. The use of dry-leaf inoculum for establishment of commom bacterial blight of bean. Plant Di sease, St. Paul, v. 72, p. 385-389, 1988.

5. Ito, M. F., Valarini, P. J., Patrício, F. R. A., Sugimori, M. H. Detecção de Xanthomonas campestris pv. phaseoli e fungos em sementes de feijão produzidas no Estado de São Paulo. Summa Phytopathologica, Jaboticabal, v. 23, n. 2, p. 118-21, 1997.

6. Lollato, M. A. Produção de sementes. Circular IAPAR, Londrina, n. 63, p. 257-279, 1989.

7. Mabagala, R. B. The effect of populations of Xanthomonas campestris pv. phaseoli in bean reproductive tissues on seed infection of resistant and suscetible bean genotypes. European Journal of Plant Pathology, v. 103, n. 2, p. 175-81, 1997.

8. Maringoni, A. C., Komori, N. Levantamento das bacterioses do feijoeiro no Estado do Paraná. Fitopatologia Brasileira, Brasília, v. 14, p. 241-4, 1989.

9. Maringoni, A. C., Fregonese, L. H., Tófoli, J. G., Kurozawa, C. Reação foliar e da vagem de feijoeiro à Xanthomonas campestris pv. phaseoli e transmissão da bactéria pelas sementes. Fitopatologia Brasileira, Brasília, v. 18, p. 412-5, 1993.

10. Maringoni, A. C., Kimati, H., Kurozawa, C. Desenvolvimento de meio de cultura semi-seletivo para Xanthomonas campestris pv. phaseoli. Científica, São Paulo, v. 22, p. 227-88, 1994.

11. Maringoni, A. C., Kimati, H., Kurozawa, C. Presença da Xanthomonas campestris pv. phaseoli em sementes de feijoeiro e conseqüências epidemiológicas. Fitopatologia Brasileira, Brasília, v. 20, p. 449-457, 1995.

12. Maringoni, A. C. Método de quantificação de Xanthomonas campestris pv. phaseoli em sementes de feijoeiro. Curso de detecção de Xanthomonas campestris pv. phaseoli em sementes de feijoeiro. Campinas: CATI, 1996, 8 p.

13. Opio, A. F. Studies on seed transmission of Xanthomonas campestris pv. phaseoli in common beans in Uganda. African Crop Science Journal, Grahamstow, v. 1, n. 1, p. 59-67, 1993.

14. Rava, C. A., Zimmermman, M. J. O., Romeiro, R. S. Inheritance of resistance to Xanthomonas campestris pv. phaseoli (Smith) Dye in Phaseolus vulgaris L. Revista Brasileira de Genética, Ribeirão Preto, v. 10, p. 709-27, 1987.

15. Rava, C. A., Sartorato, A., Romeiro, R. S. Avaliação de cultivares de feijoeiro quanto à resistência a Xanthomonas campestris pv. phaseoli em condições de campo e de casa de vegetação. Summa Phytopathologica, Jaboticabal, v. 16, p. 83-91, 1990.

16. Rava, C. A., Sartorato, A. Crestamento bacteriano comum. In: SARTORATO, A., RAVA, C. A. (Ed). Principais doenças do feijoeiro e seu controle. EMBRAPA, 1994. p. 217-42.

17. Schuster, M. L., Coyne, D. P. Survival mecanisms of phytopathogenic bacteria. Annual Review of Phytopathology, Palo Alto, v. 12, p. 199-221, 1974.

18. Silva, A. T., Maringoni, A. C. Detecção de Xanthomonas campestris pv. phaseoli em sementes de feijoeiro. Summa Phytopathologica, Jaboticabal, v. 24, n. 1, p. 79, 1998.

19. Valarini, P. J. Método para detecção de Xanthomonas campestris pv. pha seoli em sementes de feijão. 1990.167p. Tese (Doutorado em Fitopatologia) - Escola Superior de Agricultura "Luiz de Queiroz", Universidade de São Paulo, Piracicaba.

20. Valarini, P. J. Detecção do agente causal do crestamento comum em sementes de feijão. In: MENTEN, J. O. M. Patógenos em sementes: deteç̧ão, danos e controle químico. Piracicaba: ESALQ;FEALQ, 1991. P. 53-76.

21. Valarini, P. J., Menten, J. O. M. Xanthomonas campestris pv. phaseoli em sementes de feijão: detecção por inoculação de plantas indicadoras. Revista Brasileira de Sementes, Brasília, v. 14, n. 2, p. 171-9, 1992a.

22. Valarini, P. J., Menten, J. O. M. Xanthomonas campestris pv. phaseoli: método para deteç̧ão em sementes de feijão. Fitopatologia Brasileira, Brasília, v. 17, n. 4, p. 373-83, 1992 b.

23. Valarini, P. J., Spadotto, C. A. Identificação de nichos de sobrevivência de fitopatógenos em áreas irrigadas de Guaíra, SP. Pesquisa Agropecuári a Brasileira, Brasília, v. 30 n. 10, p. 1239-43, 1995.

24. Valarini, P. J., Galvão, J. A. H., Oliveira, D. A. Xanthomonas campestris pv. phaseoli: importância do inóculo da semente na epidemiologia do crestamento bacteriano comum do feijoeiro. Fitopatologia Brasileira, Brasília, v. 21, n. 2, p. 261-7, 1996.

25. Vieira, C. Doenças e pragas do feijoeiro. Viçosa: Universidade Federal de Viçosa, 1983. 231p.

26. Wallen, V. R., Sutton, M. D. Xanthomonas phaseoli var. fuscans (Burkh.) Starr \& Burkh. on field bean in Ontario. Canadian Journal of Botany, Ottawa, v. 43, p. 437-46, 1965.

27. Wallen, V. R., Galway, D.A. Effective management of bacterial blight of field in Ontario - a 10-yr program. In: CENTRO INTERNACIONAL DE AGRICULTURA TROPICAL. Resumens analiticos sobre fríjol (P. vulgaris L.). CALI, 1980. v. 5, p. 119.

28. Webster, D. M., Atkin, J. D., Cross, J. E. Bacterial blight of snap bean and their control. Plant Disease, St. Paul, v. 67, p. 935$40,1983$.

29. Zaumeyer, W. J., Thomas, H. R. A monographic study of bean disease and methods for the control. Washington: Technical Bulletin. USDA 868, 1957, p. 65-74. 